\title{
THE EDITOR-IN-CHIEF LOOKS BACK SOME TWENTY-FIVE YEARS
}

On a beautiful summer's day in 1951 Maarten Bos and I took a walk in the gardens of the Peace Palace at The Hague during an interval between lectures at the Academy of International Law. Maarten Bos asked me whether I agreed with him that the time had come to found a Dutch periodical devoted to the study of international law. I wholeheartedly agreed with him. That conversation became the starting point for a period of planning for the realization of the idea. Both of us were lawyers mainly interested in public international law. That branch of the law we thought to be too narrow a basis, in the conditions prevailing in our country, upon which to build a legal journal. So we decided that it should also include private international law. We approached a lawyer who was generally known as an expert in that field and invited him to participate in the elaboration of our plans. Our deeply missed friend, the late Louis de Winter, promptly accepted our invitation. So, the three of us went ahead on the road to our goal.

From the outset, it was abundantly clear to us that our enterprise was destined for failure if we were to limit ourselves to publishing papers in Dutch. The circle of lawyers interested in one or both branches of international law and able to understand that language is too small to enable a publisher to offer a publication in Dutch alone. So we decided that we should encourage contributors to write their studies either in English or French or possibly in Dutch but in that case with a summary in one of those languages appended to their paper. This decision necessarily confronted us with the thorny problem of linguistic revision of the papers offered. We optimistically thought that this problem could be overcome without too many difficulties.

The next step to be taken was to find a publisher willing to run the risks of becoming involved in our experiment. We found that A.W. Sijthoff's Publishing Company Ltd., then at Leyden, was prepared to collaborate with us. It was certainly due to the insight and courage of the late Mr. S.G. van Looy, then manager of that company, that they dared to embark with us. That was the beginning of a friendly and fruitful relationship between the Company and the Review's Board of Editors, which although in different form than originally, has persisted until this very day. We have received sympathetic encouragement and able technical assistance from the management and staff ever since. We are happy and grateful to have been able to establish this successful collaboration. Without their help, this Review would never have come into being and would never have succeeded in appearing throughout a quarter of a century.

Having found a publisher, another problem arose. In order for the Review to materialize a financial structure was needed. The Sijthoff Company pointed out to us that it was likely that there would be a gap in that structure which would have to be filled up from other sources. The three of us were, however, alumni or Leyden University and consequently knew that under its aegis existed a fund, the Legatum Visserianum, which purported and purports to encourage the study of international law. We requested the administrators of that fund to 


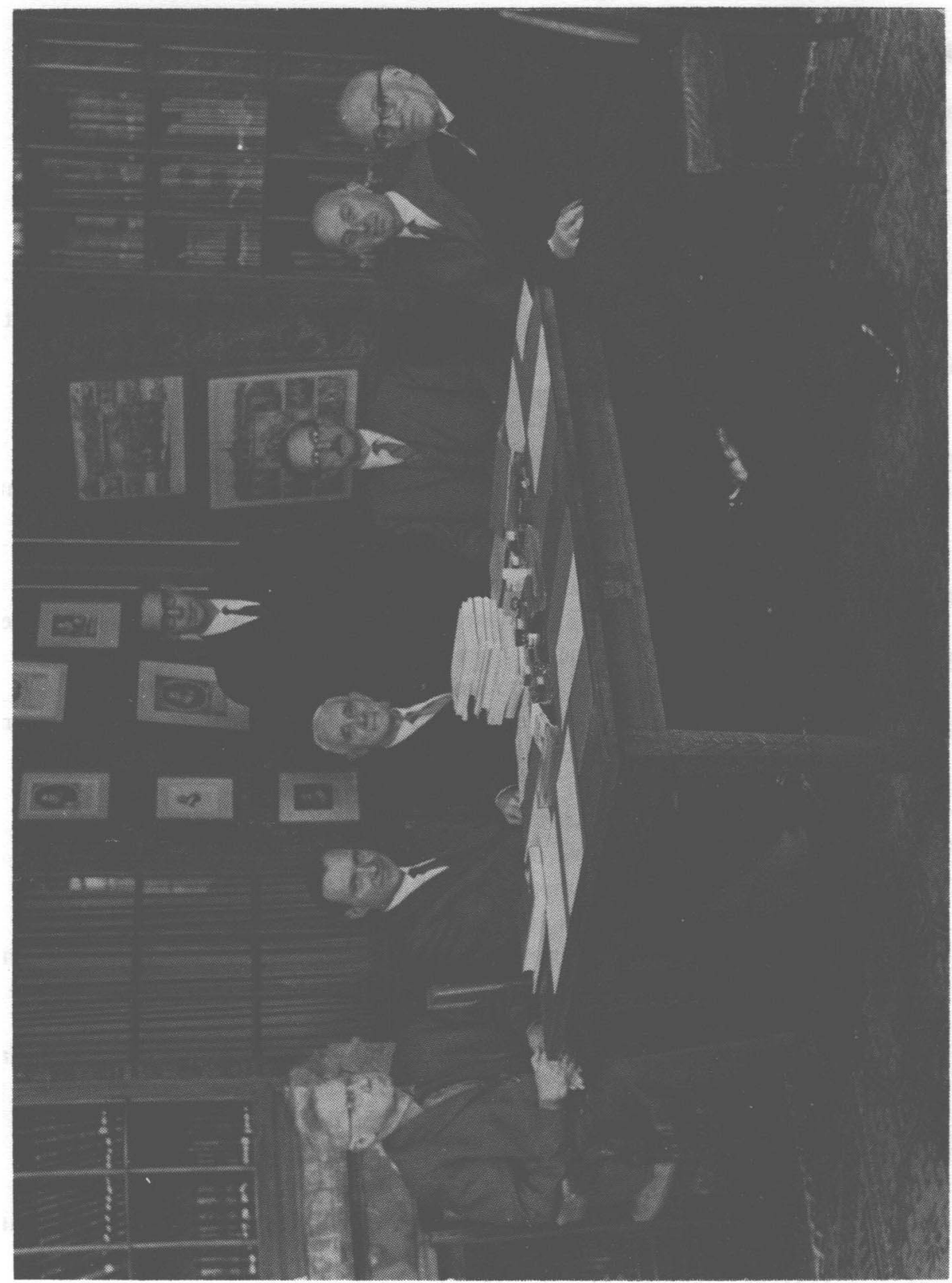

The Board of Editors during the first ten years.

From left to right: R.D. Kollewijn, L. Erades (editor-in-chief), J.H.W. Verzijl, P.M. Storm (secretary to the Board), M. Bos, L.I. de Winter, J.P.A. François.

\section{Photograph by J. Bulsing}


grant us a subvention in order that we might establish the Review. During a meeting with some representatives of the Fund's Board at the home of one of them, the late Professor R.D. Kollewijn, we explained the details of our plans. Our discussions led to the result not only that the Legatum Visserianum granted a subvention during the first two years in which the Review was to appear, but also that Professor Kollewijn and Professor J.H.W. Verzijl joined us in the further stages of preparation. We are greatly indebted to them for their wise counsel and unrelenting support.

However, the administrators of the Legatum Visserianum attached a condition to their offer. We were not to receive the grant until we had assembled a stock of copy large enough to cover the first two years of the Review. At that time, the younger three of us were not too happy with that condition, but in retrospect, one must admit that there was wisdom in it. It forced us to invite everyone in the Netherlands who had some standing either in the field of public international law or in that of private international law to favour us with a con. tribution. The necessity of carrying on this correspondence had the advantage that we automatically gave publicity to our plans to start publication of our Review. Although the response to our invitations was very encouraging, the actual number of papers sent to us for publication was not enough to meet the condition fully. The Legatum Visserianum mitigated its demand somewhat and so we were able, happily and proudly, to present to the public the first issue of the Review in October 1953.

We were honoured that "the grand old men" in both branches of international law, the late Professor Jonkheer W.J.M. van Eysinga and the late Professor E.M. Meijers opened the first issue with a joint introduction and that outstanding Dutch scholars such as Professors van Eysinga, J.A. van Hamel, J. Offerhaus and Verzijl contributed articles to it. The Secretary-General of the Hague Conference of Private International Law, Mr. M.H. van Hoogstraten, also published his first report on the progress of the work of that organization within its pages. Also included in that issue were a book review, digests in English of cases concerning public or private international law decided by Dutch courts, a selected survey of literature on public and private international law as classified by the Library of the Peace Palace during a three month's period in 1953 and some documents. Finally, the Board of Editors revealed in a Foreword its aim in publishing the Review and what would be the policy to be followed. I have already explained part of its motives, but I want to complete the image by quoting a few sentences written then:

"The Review intends to be a scientific periodical in which Netherlands jurists - whatever their position - will be able to follow the developments of both spheres of the law which it is designed to cover, and in which, on the other hand, foreign jurists will be enabled to find the contributions made to that development by the Netherlands. Our aim is to attain the highest possible standard in our chosen field. The Review does not represent any official opinion ... We would, however, fail in our object if we were not prepared to invite our foreign colleagues to co-operate. We will gladly offer the opportunity to contribute to the Review to any foreign author. ..". 
All this happened some twenty-five years ago. There came a second issue, followed by many, many, further issues. Some members have left the Board of Editors, new members have joined it. Some of the features it intended to pursue could be introduced only in the course of time, others had to be relinquished for various reasons. We made mistakes, of course, but fortunately, none of them turned out to be fatal. We always tried to learn from our mistakes. It is tempting to someone who has witnessed it all to give a detailed account of events, but that would surpass what I intend to do, which is to note some personal recollections. Suffice it to highlight some major developments which have occurred in the twenty-five years that have passed. The Netherlands Ministry of Foreign Affairs took an interest in our Review and meets part of our expenditure, while leaving us completely free to publish what we deem fit. Without this aid we would never have reached our twenty-fifth anniversary. In the course of the years we have published three Festschriften and some special numbers. The handling of the daily work for the editorial side of the Review was first done by myself alone and later with the assistance of some younger lawyers. By 1970 this method proved to be unsatisfactory owing to lack of time. An important decision was then taken. An agreement was reached between the Board of Editors and the management and staff of the Interuniversity Institute for International Law, T.M.C. Asser Institute at The Hague which developed into an efficient and mutually appreciated relationship. The administration of the Review's daily affairs was taken over by the staff of the T.M.C. Asser Institute, the Institute's office became the hospitable home for the meetings of the Board of Editors, and we joined forces with the Netherlands Yearbook of International Law, which had already been published for some time by the Institute. Since 1973 the Institute has been able to take care of the technical production of the Review, whereas the commercial side of its exploitation has been left in the good hands of the Sijthoff company. A few years ago a younger generation of lawyers joined the Board of Editors.

The decision had to be taken to publish the Review only in English. Moreover, additional space is now devoted to documentary material and information primarily related to private international law. Throughout the entire quarter of a century an informal and friendly atmosphere has existed amongst the Members of the Board. New plans have been developed and are being developed. We are united by a common belief that both branches of international law are useful instruments in building a better world.

I earnestly hope that our efforts have done something useful to improve these instruments and may continue so in the future. 